${ }^{*}$ Central Bank of

Montenegro

\title{
Use and Limitations of the Reserve Requirement Policy in Montenegro
}

\begin{abstract}
Since reserve requirement is the only monetary policy instrument used in Montenegro, it has been subject to frequent amendments since the global crisis outbreak. The analysis of the monetary demand model showed that there is an active transmission mechanism of change in the reserve requirement rate on the deposits trend reflects on lending activity. Also, there is a significant impact of FDIs on deposits trending in the banking system, as well as the positive impact of turnover on stock exchange on the deposits and loans trend. Finally, it was found that the financial crisis has caused negative trends in loans and deposits. On the other hand, the impact of changes in the reserve requirement on the economic activity in Montenegro could not be determined. This is primarily due to the fact that the transmission mechanism of the effect of reserve requirement on economic activity is too long to be able to estimate the model that does not allow the dynamics of the independent variables. The second reason is that industrial output index is only an indirect indicator of the economic activity.
\end{abstract}

Key words: reserve requirement, monetary transmission mechanism, monetary demand model, credit expansion, Montenegrin banking system

JEL Classification: E52, C52, G01

\section{Introduction}

The analysis of efficiency of the use of reserve requirement policy as the primary or secondary monetary policy instrument underlines this research. Considering 
that the case of Montenegro is analysed in this paper, it should be borne in mind that the reserve requirement policy is the most important and the only available monetary policy instrument. In theory, there are possibilities of using open market operations and lending of last resort as the monetary policy instruments.

Solving the issue of reserve requirement implies the regulation of use of a portion of banks' assets by the central bank. The reserve requirement policy belongs to indirect monetary policy instruments as it influences indirectly the creation of money supply. The reserve requirement is treated in practice nowadays as an alternative to open market operations or as an addition that should increase the efficiency of open market operations. It should be pointed out that the reserve requirement policy is a very useful instrument when a swift response is needed to a change in reserves available to the banking system. This instrument can influence banks' lending activity and thus a very important instrument for regulating demand. Also, this instrument can influence the balance of payments trending through the regulation of demand.

As stated above, the conclusion can be drawn that the reserve requirement has two primary roles. The first role is of prudential character since it helps the financial system stability through the regulation of banks' liquidity. The second one represents the reserve requirement as an instrument of transmission of monetary policy measures on economic activity and inflation through the regulation of credit supply. An important feature of reserve requirement is its safety effect. It means that in the case of a bank bankruptcy, its creditors are settled from the bankruptcy pool of assets which can be increased by the amount of allocated reserve requirement held with the central bank. Therefore, it is not uncommon that when there is low credibility of the banking system and after banking crises, the policy of high reserve requirement rate is conducted in order to restore the confidence of depositors in the banking system.

The remainder of the paper is structured as follows. A literature review is given in the second chapter. The third chapter presents an empirical testing of the reserve requirement policy effects in Montenegro. The fourth chapter lays out the interpretation of results and discussion, while the fifth chapter ends with concluding remarks.

\section{Literature Review}

The existing dollarization regime largely narrowed the activity of monetary policy of the Central Bank of Montenegro. The main assumption in economic 
literature is that the corresponding changes in monetary policy lead also to the changes in real flows, at least for a short period (Romer \& Romer, 1989; Bernanke \& Blinder, 1992). Although price stability is considered as the main monetary policy objective, other objectives are also mentioned like: economic growth, high employment, and the stability of interest rate and financial markets. However, the literature is much less certain when it comes to channelling the effects of monetary flows on real flows. In that respect, according to Bernanke and Getler (1995), the transmission process of the effects of monetary flows on real flows is treated as the "black box".

The basis of this research is to determine the importance of traditional approach to the reserve requirement as monetary instrument in a dollarized economy where this instrument has specific weight. The main assumption is that the reserve requirement in dollarization has a strong stabilisation effect: monetary authorities reduce the reserve requirement rate when economic activity is below the potential, i.e. they increase it when there is boom in economic activity. The model that assesses the effects of changes in the reserve requirement rate is based on the credit channel theory (Kashuap \& Stein, 1994) which implies that the reserve requirement growth influences a decline in deposit supply, which further affects a decline in loans, resulting in a decline in investments in the corporate sector and a decline in economic growth.

The literature that contains empirical analysis of the effects of a change in reserve requirement on monetary aggregates is very limited. To wit, the current literature focuses on theoretical approach, simultaneously neglecting the testing of an assumed direct impact of the change in the reserve requirement rate on monetary aggregates. The main objective of this research is to analyse the effects of the reserve requirement policy on financial (loans, maturity structure of deposits) and real variables (GDP and investments). Furthermore, this paper investigates whether the reserve requirement policy can influence these variables and how the reserve requirement policy should be formulated in the forthcoming period to achieve optimum macroeconomic performances.

In theory, it is usually considered that the introduction of differentiated reserve requirement rates could influence the maturity structure of deposits if such rate is higher on deposits with shorter maturity and vice versa. However, in countries with a relatively low level of the banking system credibility, the population is not keen on placing long-term deposits. This research also tests whether the current reserve requirement policy in Montenegro has influenced the improvement of the maturity structure of deposits. 
Moreover, the efficiency of effects of the reserve requirement on the banks' lending activity is also assessed. Although it would be common to expect that the increase of reserve requirement or the expansion of the base for the calculation of the reserve requirement would reduce banks' available liquid assets and consequently their lending activity, the practice has shown that this sequence of events is not necessarily achieved. On one hand, banks have developed a wide spectrum of instruments and techniques that successfully circumvent the allocation of the reserve requirement in practice. This means that if the reserve requirement rate increases in countries that have developed financial markets, deposit substitutes will increase (e.g. certificate of deposits), while there are significant deposit substitutes in countries where the financial market is underdeveloped. When it comes to developing countries, it can be concluded that there is no danger of avoiding the allocation of the reserve requirement by banks. On the other hand, increased allocations can be treated only as an additional expense, which means that the loan for end users becomes more expensive and lending activity is does not subside.

As it has been already mentioned, the reserve requirement is the only real monetary policy instrument in Montenegro. Thus, all things considered, the notion can be accepted that the reserve requirement policy is a synonym for monetary policy. It also begs a question whether monetary policy can influence GDP trends in a dollarization environment. This research also tries to answer this question.

\section{Empirical Testing of Effects of the Reserve Requirement Policy in Montenegro}

\subsection{Methodology and availability of data}

The impact of reserve requirement on the level of deposits, loans and economic growth is estimated on the basis of the monetary demand model. The main hypothesis which should be tested is the impact of a change in reserve requirement on the rates of growth in deposits and loans. An appropriate estimated aggregate demand model is based on certain assumptions, restrictions and generalizations in accordance with economic theory, in order to estimate the model efficiently. The model is based on the monetary demand model:

$$
\left(M^{*} / P\right)=f\left(Y, R_{i}\right)
$$

where $\mathbf{M}^{\star}$ represents a certain aggregate of monetary demand, $\mathbf{P}$ represents the level of prices, $\mathbf{Y}$ is available income, and $\mathbf{R}_{\mathbf{i}}$ is the real interest rate. All values in 
the model (deposits, income, interest rate, etc.) are expressed in nominal values; therefore, the estimated model is consistent with the monetary demand model.

In order to determine a potential impact of a changed rate of reserve requirement on the level of deposits, loans and economic growth, a linear partial adjustment model (PAM) is estimated. This model will be implemented in order to estimate the impact of reserve requirement change on the growth rate of deposits, loans and economic activity. Time series that are used in this paper covers March 2003 to June 2010, which represents 100 monthly observations. Before the model estimation, it is necessary to perform the differentiation of time series in order to avoid the problem of estimation of spurious regression. Therefore, time series that are stationary will be used in the model, mainly lagged differentials of continuous variables and differentials of variables which are expressed as a percentage so it does not make sense to calculate growth rates for them. ${ }^{1}$

\section{Table 1: Short description of variables}

\begin{tabular}{|c|c|c|c|}
\hline Variables & Short description of variables & Mean & $\begin{array}{l}\text { Standard } \\
\text { deviation }\end{array}$ \\
\hline DEPOSITS & Level of deposits may 2003-2010, 000 EUR & 977242.6 & 787975.4 \\
\hline LOANS & Level of loans, may 2003-2010, 000 EUR & 1127261 & 1057937 \\
\hline INTERESET_R & Average weighted active interest rate, $\%$ & 10.8 & 1.78 \\
\hline FDI & Net inflow of foreign direct investments, May 2003-June 2010, 000 EUR & $4.55^{*} 10^{7}$ & $5.02 * 10$ \\
\hline RESERVE_R & Level of reserve requirement, 2003-2010, EUR & 1202240.1 & 90928.7 \\
\hline TURNOVER_SE & Level of turnover on the stock exchange, 2003-2010, EUR & 20000000 & $2.99 * 10$ \\
\hline DUMMY1 & Takes value 1 for regime of reserve requirement 1 , otherwise 0 & 2.3 & 4.6 \\
\hline DUMMY2 & Takes value 1 for regime of reserve requirement 2 , otherwise 0 & 2.3 & 4.7 \\
\hline DUMMY3 & Takes value 1 for regime of reserve requirement 3 , otherwise 0 & 3.8 & 5.9 \\
\hline DUMMY4 & Takes value 1 for regime of reserve requirement 4, otherwise 0 & 4.8 & 6.6 \\
\hline DUMMY5 & Takes value 1 for regime of reserve requirement 5 , otherwise 0 & 5.5 & 5.8 \\
\hline DUMMY6 & Takes value 1 for regime of reserve requirement 6 , otherwise 0 & 3.4 & 7.2 \\
\hline DUMMY7 & Takes value 1 for regime of reserve requirement 7 , otherwise 0 & 0.8 & 2.6 \\
\hline DUMMY8 & Takes value 1 for regime of reserve requirement 8 , otherwise 0 & 0.8 & 2.6 \\
\hline DUMMY_FC & 1 for start of financial crisis October 2008 & 1.7 & 4.7 \\
\hline
\end{tabular}

Source: Author's calculations

1 Even though there is a correlation between variables, it is important to emphasize that due to estimations and checking of VIF values (Variance Inflation Factor), potential multicollinearity in any equation is not evidenced. Due to the model specificity, the aim was to get the results which will be efficient from the point of view of potential heteroscedasicity, multicollinearity and autocorrelation. In the cases of all three univariate models, no high level of multicollinearity was evident (they did not exceed cumulative value 4). 


\subsection{Estimation of the impact of the reserve requirement change on the deposits growth rate in the Montenegrin banking system}

Primarily, the hypothesis was tested that the reserve requirement represents efficient instrument of monetary policy that has a direct impact on the growth rate of deposits. Total deposits are chosen as monetary aggregate that is actually a dependent variable. Differentiated approach of the reserve requirement policy existed until 2008 and it was generally used to influence maturity structure of deposits. However, it represents an active instrument that is used in order to influence the liquidity of the banking system.

The model is based on the monetary demand model, and it is modified according to available variables, but in essence, it does not deviate from theoretic assumptions. According to the monetary demand model, the main assumption is that the increase in the reserve requirement will be reflected through the decrease in deposits. Also, in line with empirical research of Barro (1990), variable turnover on stock exchange is included in the regression, i.e. growth rate of Moste index. In accordance with theory, the assumption is that the increase of turnover in stock exchange will have positive impact on the growth of lending activity, growth of real economy, that will therefore reflect on the increase of deposits, i.e. it is expected that coefficient in front of variable DlnMoste will be positive and significant.

Similarly, there is variable growth rate of foreign direct investments included in the regression. Based on the theory, the accelerated FDI leads to economic growth and disposable income, and the assumption is to expect positive sign in front of the coefficient of this variable. The reserve requirement rate according to assumption should have negative and significant impact on growth rate of deposits. Finally, dummy variables are also included in the regression, which should control changes of the reserve requirement regime ${ }^{2}$, and Dummy_FC, which should control emergence of the financial crisis, and for which is supposed negative sign in front of the coefficient. Few variables are excluded from the final version of model. Namely, some of the variables were not significant and some of them had high VIF factor which means that there is high multicollinearity in the model.

The results obtained confirm the initial assumption that the growth of the reserve requirement rate has negative impact on the deposits growth rate. Namely,

2 In order to avoid "multicollinearity trap", Dummyl is excluded from model and is deemed as benchmark dummy variable. 
growth rate of the reserve requirement of one percentage point leads to the decline in deposits of $0.3 \%$. Based on the results, it might be concluded that there is a significant positive impact of growth of the turnover on the stock exchange measured by the index Moste on the deposits growth. In addition, there is a positive and significant impact of foreign direct investments. Growth of FDI of one percentage point leads to the increase in deposits of $1.6 \%$, on average.

On the other hand, growth of industrial output has positive but not significant impact, which has to approximate BDP growth rate. This result is expected since only indirect impact of this real aggregate indicator on the deposits growth rate may be expected. Furthermore, according to the expectations, significant negative impact of financial crisis on deposits growth is evident; therefore dummy variable that approximate financial crisis occurrence has significant negative coefficient. Finally, negative but not significant sign in front of lagged deposits growth rate is expected.

\subsection{Estimation of the impact of the reserve requirement change on the growth rate of loans in Montenegrin banking system}

There are divided opinions on the impact of the reserve requirement rate on the credit channel in the empirical literature. According to Romer and Romer (1993), the reserve requirement has been actively used earlier by Fed. For example, it was used during 1936 and 1937 when Fed doubled its reserve requirement, which led to big contractions of economy because of the restrictive monetary policy ${ }^{3}$, when the banking sector reacted with significant decrease of lending activity in order to retain the level of adequate liquidity.

In the case of Montenegro, the reserve requirement has been used in both directions. In the period of credit boom during 2006 and 2007, the Central Bank of Montenegro had impact on the decrease in lending activity, while when the financial crisis occurred in September 2008 it began using this instrument to improve liquidity in the banking system as well as to improve lending activity.

As for the previous model, this model is also based on the monetary demand model, and it is modified taking into account available variables. Although loans do not represent one of the aggregates of monetary demand, there is high positive correlation between these two variables (0.96), thus substitution of variables is performed.

3 See Friedman and Jacobson-Schwartz (1963). 
The main assumption is that growth of the reserve requirement will impact the decrease in deposit potential and that banks will try to retain adequate liquidity by decreasing lending activity. Namely, the reserve requirement as monetary instrument increasingly stops to be the tool for preventing rapid outflow of money from the banking system (bank run), but it largely represents an instrument used for active credit policy of banks. Cargill and Mayer $(2006)^{4}$ have found that growth in the reserve requirement leads to situation where banks accumulate liquidity reducing at the same time lending activity. Loungani and Rush (1995) found that an increase in the reserve requirement leads to an increase in commercial lending activity, investments and economic growth.

Finally, Romer and Romer (1993) ${ }^{6}$ pointed through the empirical work that the reserve requirement is an extremely strong mechanism in the system of the Fed (the USA post-war period), which significantly caused the credit activity of the banking system. They found that during all periods of recession (1966, 1968-69, 1974, 1978-80), the recession occurred after the Fed made significant interventions to the reserve requirement. They concluded that after 1980, the Fed was less interested in using this instrument of monetary policy. Therefore, hypothesis that is taken into account before estimation of model is that coefficient in front of variable dlnReserve_r has negative impact.

In accordance with empirical research of Barro (1990), turnover on the stock exchange, i.e. growth rate of turnover on the stock exchange is included in the regression. Barro (1990) found that fluctuations in the turnover on the stock market have a strong impact on investments and lending activity growth. It is assumed that growth of the turnover on stock market will have positive impact on lending activity growth.

Rate of change in interest rate is also in the monetary demand model. According to the literature, the majority of authors confirm the existence of a negative relation which supposes that a decrease in interest rates has impact on credit demand growth (Amonoo, Acquah \& Asmah, 2003) and vice versa. Therefore, the initial hypothesis in this paper, according to Mc Kinnon (1973) and Shaw (1973), is that interest rate growth leads to a decrease in lending activity. Finally, few dummy variables are placed in the model in order to control the changes in the reserve requirement regime, as well as the dummy variable which has to control the occurrence of financial crisis.

\footnotetext{
4 See Cargill and Mayer (2006).

5 See Loungani and Rush (1995).

6 See Romer and Romer (1993).
} 
The results obtained confirm the existence of the credit channel, i.e. the initial assumption that growth rate of the reserve requirement has a negative impact on the growth of loans. Namely, on average, growth rate of the reserve requirement by 1 percentage point leads to decline in loans of 0.2 percent. Based on the results of partial adjustments model, it can be seen that there is a significant positive impact of the growth of foreign direct investments on the credit growth, which may be explained by the increase in disposable income due to large inflow of foreign direct investments and the deposit growth. Thus, we can accept the hypothesis that FDI growth of 1 percent on average leads to an increase in loans of 0.5 percent.

Contrary to the assumption, the model indicates positive impact of interest rates on lending activity, which suggests that dynamic component should be introduced to model this impact because the least squares method is unable to determine the dynamic dependence of lending activity in relation to changes in interest rates. Intuitively, it is logical that an increase in the interest rate leads to a decline in lending activity. Author emphasizes that, in the case of Montenegro and given the fact that it is dollarized economy, the interest rate is completely inflexible and rigid in relation to Euribor or change in country risk, acting as a kind of autoregressive process.

On the other hand, growth of industrial output has negative but insignificant impact. It should be emphasised that this variable, regardless of the fact that it is negative and insignificant, is retained in the model due to specification of monetary demand equation.

According to the expectations, a significant negative impact of the financial crisis on the growth of loans is evident. Dummy variable that approximates financial crisis occurrence has negative significant coefficient. Finally, negative and insignificant sign in front of lagged growth rate of loans is expected.

\subsection{Estimation of the impact of the reserve requirement change on the economic growth in Montenegro}

Since there is no adequate approximation of GDP on monthly or quarterly level, the industrial output is the only logical and available approximation that captures about $40 \%$ of total activity of the Montenegrin economy. This represents the largest limitation of the model. However, due to fact that all other variables are available on monthly basis and that macroeconomic variable in the model is available only at annual level, certain compromise had to be made. 
Compared to the previous two models that are estimated, this one was the most challenging. First of all, the empirical literature that is related to the impact of the reserve requirement on the economic growth is very limited. Therefore, the model of Loungani and Rush $(1995)^{7}$ is followed. They estimated the impact of the reserve requirement on investments and GDP. The initial assumption is that the reserve requirement represents a kind of taxation of banking deposits, which leads to the decrease in lending activity and the decrease in GDP growth rate.

However, according to Slovin, Sushka and Bendeck (1990), the reserve requirement do not have direct impact, neither on credit channel, nor on real flows. According to their empirical conclusion, the increase in the reserve requirement rate leads only to distortions in the financial market; the financial result of banks is reduced and it leads to the increase in activities and intermediation between the rest of the financial markets (insurance companies, mutual funds), so that it wipes out the impact of this instrument on real flows.

In the case of Montenegro, given the time horizon in which the database is taken, the other elements of the financial market either do not exist or are at an early stage of development. Therefore, the assumption is that the change of the reserve requirement rate could still have an impact on real flows and that the other elements of the financial market could not "dilute" the impact of this monetary instrument on real flows.

The second limiting factor is the potential endogeneity between GDP and the reserve requirement, i.e. a high level of causality. The decrease in GDP leads to the reduction in demand for loans, while the reduction in lending activity causes that monetary authorities encourage credit activity through changes in the reserve requirement. This is much more serious problem, which cannot be controlled by the selected method. Therefore, at the database there is no quality of instrumental variables with which we could control the endogeneity, so the results should be taken with caution, given the potential endogeneity of the dependent and the main independent variable.

One of the constraints is the specification of the model which does not contain sufficient dynamics that could "hold" the two effects - the impact of the reserve requirement on loans, and the impact of the credit activity on the real sector. ${ }^{8}$

\footnotetext{
7 See Loungani and Rush (1995).

8 In the case of VAR models, it is important to note that the effect of changes in the reserve requirement on macroeconomic variables is very long and that even with the VAR model it is very difficult to identify this effect.
} 
Also, instead of variable M1 that represents monetary base, which is used in the model of Loungani and Rush (1995), deposit growth rate is used in the specification of the model, which represents the largest item in the monetary base in Montenegro. ${ }^{9}$ In line with the empirical work of Barro (1990), turnover in the stock market is included in the regression, i.e. the growth rate of the turnover in the stock market. Barro (1990) found that fluctuations in the turnover on stock market have strong impact on investments and economic growth. It is assumed that turnover growth in the stock market will have a positive impact on GDP growth.

Finally, the growth rate of foreign direct investments is also included in the regression. In fact, there is a very extensive literature dealing with the impact of FDI on economic growth in developing countries. On the other hand, there is a set of empirical literature that indicates the existence of weak or negative impact of FDI on economic growth (Hanson, 2001; Lipsey, 2002). The general assumption that will be taken into account in the empirical evaluation of the model is the existence of positive relationship.

According to the assumption, the reserve requirement rate should have negative and significant impact on economic activity, i.e. growth of the reserve requirement transmission mechanism of this instrument should be reflected through the decrease in lending activity and decrease in GDP. Few dummy variables are also included in the regression that should control changes of reserve requirement regimes as well as dummy variable which has to control occurrence of financial crisis.

The results obtained show that there is no obvious impact of the change of the reserve requirement rate on the economic growth. Namely, none of the variables has significant impact on the economic growth. That is logical because the reserve requirement is too "weak" instrument of monetary policy to have an impact on economic growth.

The model does not meet the basic econometric assumptions that the results have the character of the best linear unbiased estimators. In fact, it is evident that there is a problem of functional form which indicates that the model is not well specified. Transmission of the change in the reserve requirement rate on economic growth implies much longer lag effects compared to static model. High coefficients in front of variables, together with high standard error, indicate to inad-

9 It is not possible to calculate Montenegrin monetary base since the precise amount of cash is unknown. The Central Bank of Montenegro stopped publishing M1 monetary aggregate data in 2008 . 
equate specification of the model. Thus, PAM do not represent an efficient model and, in the future, it is necessary to do the re-estimation of the model that would not only encompass the dynamics of the model but at the same time it would control the potential endogenity of the impact of the economic growth on the reserve requirement policy. Given the data limitations, the author believes that has chosen the most efficient specification of the model which, from the perspective of robustness and sensitivity to the problems of autocorrelation, multicollinearity and heteroscedasticity, produces effective results.

\section{Interpretation and Discussion}

Dollarization has influenced that the monetary policy instruments of the Central Bank of Montenegro have been largely limited. The reserve requirement policy is an instrument of monetary policy that does not have a large influence as some other monetary policy instruments, but it is the only one at the CBCG disposal and therefore its use should be optimised. The main question is how to use this instrument and which variables it can influence?

The reserve requirement policy may be used to improve the maturity structure of deposits. Such policy entails the pursuit of differentiated reserve requirement policy which calculates a higher reserve requirement rate for demand deposits and/or short-term deposits, while a lower or a zero reserve requirement rate is used for long-term deposits. Banks are thus encouraged to offer to their clients more favourable conditions for placing long-term deposits as they bear lower expenses for banks. Such reserve requirement policy is similar to the reserve requirement policy used by the ECB which envisages that the reserve requirement is not calculated for deposits with the maturity exceeding two years. This form of the reserve requirement policy was also used by the CBCG in the pre-crisis period.

There is also a possibility that the reserve requirement policy affects the trending of lending interest rates. In theory, a lower effective rate of reserve requirement means lower costs for banks and thus they have the possibility to reduce lending interest rates. Even besides dollarization, interest rates in Montenegro are high, and they have adverse effects on economic growth. ${ }^{10}$ It makes sense though to use the reserve requirement for this purpose.

\footnotetext{
${ }^{10}$ At end-July 2010, the weighted lending effective interest rate amounted to $9.6 \%$. For more details see: Central Bank of Montenegro, 2010.
} 
However, empirical research conducted in 2006 showed that the reserve requirement rate does not affect the trending of lending interest rates in the long run. ${ }^{11}$ It is highly likely that if the reserve requirement effective rate fell drastically, lending interest rates would decline but such a decline would not be so severe. Consequently, total amount of the allocated reserve requirement would "melt away" drastically and it could not be used for any other purpose. Other factors affect much more the level of interest rate in Montenegro like: country risk, client risk, the quality of offered collateral, profitability of potential projects, and the like. It can be concluded that the use of reserve requirement in Montenegro for this purpose would not be most suitable.

The reserve requirement instrument can be used to cease a credit boom. Theoretically, this can be achieved in two ways. The first way is to introduce reserve requirement on foreign interbank loans, while the other way is to increase the current effective reserve requirement rate that also reduces banks' credit potential. The reserve requirement policy was used for this purpose by most countries in the region during the pre-crisis period and the success largely varied across the countries. This often meant an increase in banks' costs that they just spilled over to their clients by increasing interest rates. In the period of overheated demand and excessive lending, the CBCG also used the reserve requirement policy for this purpose. This paper showed through econometrics that the reserve requirement rate of growth of one percentage point leads to a decline in lending of 0.2 percent. However, bearing in mind the fact that banks usually find the way to "bend" these rules or just transfer these costs over to their clients, the reserve requirement policy should be used in Montenegro only in case of some major disturbances and/or excessive credit expansion that cannot be stopped in any other way.

Another possibility is to use the reserve requirement policy in order to influence liquidity in the banking system. This theoretically means that when you reduce liquidity in the banking system, the reserve requirement rate also reduces, and thereby increases liquid assets of banks. After the outbreak of the global financial crisis, when by the liquidity of the banking system was jeopardized, the CBCG policy at the time was to gradually lower reserve requirement to allow for the option of extending loans against the reserve requirement for a longer period

\footnotetext{
11 More details: Central Bank of Montenegro, 2006.
} 
of time. ${ }^{12}$ Bearing in mind that financial stability is the constitutionally defined responsibility of the CBCG, one gets the impression that this is the actual purpose for which you need to use reserve requirement. The global financial crisis has clearly shown that a collapse of the banking system is much more dangerous than inflation growth. ${ }^{13}$ Thus, in a crisis situation that threatens one or more systemically important banks, one should not hesitate to apply this monetary policy instrument (significantly lowering of reserve requirement) as it is of great importance in a crisis to timely provide liquid assets to banks of extreme importance. This function is even more significant for banks that do not have parent banks (at least three of eleven currently licensed banks in Montenegro). The crisis has shown that parent banks can play the role of the lender of last resort, but for banks that do not have parent banks, the central bank is the only source. Therefore, this monetary policy instrument should be primarily used in the function of preserving the banking system stability through influences on banks' liquidity.

\section{Concluding Remarks}

Reserve requirement is the most important monetary instrument of the Central bank of Montenegro. Since the activating of this instrument to date, many aspects of this instrument have changed. The most important are the reserve base and rate, which have had the biggest influence and the greatest effects.

The use of the reserve requirement policy by the Central Bank of Montenegro primarily affects liquidity of the banking system, and indirectly affects the stability and confidence in the banking system. Also, using this instrument, the Central Bank of Montenegro influences the level of lending activity, i.e. indirectly it has effects on the money supply in the economy. Besides that, the reserve requirement policy change potentially impacts the maturity structure of deposits.

The results obtained point to a conclusion that there is an active transmission mechanism between a changed reserve requirement rate and the deposits trend,

${ }^{12}$ Until the global crisis outbreak, loans against reserve requirement could be used for one day (intraday loans). In the crisis, the enactment of the Law on Protection of the Banking System and amendments to the pertinent CBCG secondary legislation enabled the use of these loans for the period of ten business days. Such a loan could practically be used for a longer period of time because in case of the loan default, the beneficiary bank would be only subject to a higher default interest.

${ }^{13}$ In case of the banking system crash, the economy is practically paralysed, whereas in a high inflation environment (unless it escalates into hyperinflation), the economy can operate with certain difficulties and/or increased expenses. 
which reflects on the lending activity. In addition, the results showed that foreign direct investments also affect deposits in the system, indicating positive effects of the stock market turnover on both deposits and loans. It also proved that the financial crisis triggered negative trends of loans and deposits. However, the obtained results show that reserve requirement is too "weak" instrument of monetary policy that it could have an impact on economic growth.

Since the reserve requirement is the only monetary policy instrument in Montenegro, special attention should be made for optimising this instrument. It may be used in the case of excessive credit boom, but it should be used for this purpose only if there is no other instrument that can stop credit boom. The reserve requirement policy should be used in order to impact the liquidity of the banking system during the crisis. When there is a serious crisis, monetary authorities should not hesitate to lower the reserve requirement radically. However, the reserve requirement should be gradually increased after the crisis until it reaches pre-crisis level, in order to preserve this instrument for the future.

One of the crucial issues is an optimum reserve requirement rate. If set too high, it would burden banks and lead to soaring interest rates. On the other hand, if being too low, it would prevent efficient application of this instrument. Therefore, it is very difficult to speak in conclusive terms of the reserve requirement rate that should be set in Montenegro. However, the rule of thumb for the optimum rate is between $8 \%$ and $10 \%$. 


\section{References}

1. Amonoo, E., Acquah P. K. \& Asmah E. E. (2003). The Impact of Interest Rates on Demand for Credit and Loan Repayment by the Poor and SMEs in Ghana, Impact of Financial Sector Liberalization on the Poor. International Labour Office Research Paper 03-10.

2. Barro R. J. (1990). The Stock Market and Investment. Review of Financial Studies 3 (1), 115-131.

3. Bernanke, B. S. \& Blinder, A. S. (1989). The federal funds rate and the channels of monetary transmission. Federal Reserve Bank of Philadelphia Working Papers 89-10.

4. Bernanke, B. S. \& Gertler, M. (1995). Inside the Black Box: The Credit Channel of Monetary Policy Transmission. National Bureau of Economic Research Working Paper 5146.

5. Cargill, T. F. \& Mayer, T. (2006). The effect of changes in reserve requirements during the 1930s: The evidence from nonmember banks. Journal of Economic History, 66(2), 1-16.

6. Central Bank of Montenegro. (2006). Empirical research on the impact of reserve requirement on the key financial variables in Montenegro. Central Bank of Montenegro Working paper 9.

7. Friedman, M. \& Jacobson Schwartz, A. (1963). A Monetary History of the United States 1867-1960. Princeton: Princeton University Press.

8. Hanson, G. H. (2001). Should Countries Promote Foreign Direct Investment? United Nations, G-24 Discussion Paper 9.

9. Kashyap, A. K. \& Stein, J. C. (1994). The Impact of Monetary Policy on Bank Balance Sheets. National Bureau of Economic Research Working Paper 4821.

10. Lipsey, R. E. (2002). Home and Host Country Effects of FDI. National Bureau of Economic Research Working Paper 9293.

11. Loungani, P. \& Rush, M. (1995). The Effect of Changes in Reserve Requirements on Investment and GNP. Journal of Money, Credit and Banking, 27(2), 511-26.

12. McKinnon, R. I. (1973). Money and Capital in Economic Development. Washington D.C: The Brookings Institution.

13. Romer, C. D. \& Romer, D. H. (1993). Monetary Policy Matters. Journal of Monetary Economics, 34, 75-88.

14. Shaw, E. S. (1973). Financial Deepening in Economic Development. New York: Oxford University Press.

15. Slovin, M. B., Sushka, M. E. \& Bendeck Y. M. (1990). The market valuation effects of reserve regulation. Journal of Monetary Economics, 25, 3-19. 